Original Research Article

\title{
Study on functional outcome of the proximal humeral internal locking system (PHILOS) for displaced proximal humeral fractures in adults
}

\author{
Rao N.V.N. ${ }^{1}$, Supradeeptha C. ${ }^{2}$ \\ ${ }^{1}$ Dr. N.V. Narasimha Rao, Associate Professor, ${ }^{2}$ Dr. Challa Supradeeptha, Associate Professor; both authors are attached with \\ Department of Orthopaedics, GSL Medical College \& General Hospital, Rajahmundry, Andhra Pradesh, India.
}

Corresponding Author: Dr. Challa Supradeeptha, Associate Professor, Department of Orthopaedics, GSL Medical College \& General Hospital, Rajahmundry, Andhra Pradesh, India. Email: supradeep_challa@yahoo.co.in

\begin{abstract}
Background: The Incidence of trauma related skeletal injuries have been on the rise in recent years and proximal humerus fractures are one of the most common fractures occurring in the human body. Hence the present study was conducted to evaluate the clinical and functional outcome of the proximal humeral internal locking system (PHILOS) technology. The present study was undertaken to assess the functional and radiological outcome of the proximal humeral internal locking system (PHILOS) for displaced proximal humeral fractures in adults. Method: The present prospective observational study was conducted in adults with proximal humerus fractures admitted to department of orthopedics, GSL Medical College and General hospital Rajahmundry during study period from $1^{\text {st }}$ October 2015 to $31^{\text {st }}$ March 2017 . The study was approved by the institute's ethical committee. Patients were undergoing Open reduction internal fixation with philos locking plating for the sustained fracture under general anaesthesia. Post-operative physiotherapy followed according to protocol, to evaluate the functional outcome. Result: The average age of patients was 44 years. Males were 16 and females were 09. Most common mechanism of injury observed was Road traffic accident in $72 \%$. The Constant- Murley score was significantly improved $(\mathrm{p}=.000)$ over the successive follow-up period. 01 (04\%) patient had excellent Constant-Murley scores, 11 (44\%) patients had good scores, as like $11(44 \%)$ had moderate scores and only $2(08 \%)$ patients had a poor functional outcome. Conclusion: In conclusion, the proximal humeral locking plate seems to be an adequate device for the fixation of displaced two-part, threepart and four-part proximal humerus fractures. Due to stable fixation, early functional aftercare is possible and allows the patient to regain good shoulder function and resume normal activities much earlier.
\end{abstract}

Keywords: Proximal Humeral Internal Locking System (PHILOS), Proximal humeral fractures, Constant- Murley score, Neer's classification.

\section{Introduction}

The Incidence of trauma related skeletal injuries have been on the rise in recent years and proximal humerus fractures are one of the most common fractures occurring in the human body. Fractures of the proximal humerus represent approximately $4 \%$ of all fractures and $26 \%$ of humerus fractures $[1,2]$. It is the most common type of fracture in an elderly population with osteoporotic bone, Three fourths of the fractures occur in older individuals with an occurrence three times more often in women than in men.In patients above the age of 65 years proximal humeral fractures are the second most frequent upper extremity fractures, next to distal end radius fractures. The most serious fractures and fracture dislocations are often seen in active, middle aged patients [3-8].The management of proximal humerus fractures is a challenging task to any

Manuscript Received: $4^{\text {th }}$ July 2019

Reviewed: $10^{\text {th }}$ July 2019

Author Corrected: $18^{\text {th }}$ July 2019

Accepted for Publication: 22nd July 2019 surgeon due to a wide variety of fracture patterns observed in these injuries. It leads to temporary disability and loss of working hours. Restoration of the function of the limb is of paramount importance. Multiple factors related to patient, surgeon and fixation technique govern the outcomes of these injuries. Patient-related factors like age, co-morbidity, fracture pattern, bone quality, arm dominance, activity level, professional demands, ability to comply with post operative rehabilitation protocol and more importantly the expectation of the patients from particular intervention were taken into account before proceeding with any appropriate intervention [9].

Reduction of displaced proximal humerus fractures is a challenging task as various fracture patterns can occur owing to the complex anatomy [10]. Most of the proximal humeral fractures are nondisplaced or minimally displaced and stable. These can be treated conservatively with early 


\section{Original Research Article}

rehabilitation [12-17]. Conservative management may result in nonunion, malunion, and avascular necrosis (AVN), which may lead to pain and dysfunction [12].

But severely displaced and comminuted fractures warrant surgical management for optimum shoulder function. The surgery should be carried out as soon as the patient's general condition permits. A delay of several days makes reduction more difficult and a significant delay results in absorption of bone, making secure internal fixation impossible [18].

Recentlyuse of locking compression plate has been advocated. New locking plate technology was evolved to overcome complications and failure associated with older fixation technique [19]. The combination of conventional plate technology along with newly designed locking screw is the basis for new locking plate osteosynthesis.

The principle of this technology is fixed angle relationship between the screws and plate which provide angular as well as axial stability, adequate buttressing and loadsharing support which together prevent loss of reduction and collapse of the fracture fragments.
Literature provides ample evidence which favors the use of locking plates in displaced proximal humerus fractures. The advantage of the locking compression plate is better anchorage of screws in osteoporotic bone. Because of the good fixation, enhanced stability will allow for early mobilization of the injured shoulder [20-23] studies based on biomechanical principles of implantshave shown that construct using locking plates are significantly stronger and more resilient than those using non-locking screws, intramedullary nails and blade plates [24]. Though locking plate technology was recommended for fixing proximal humeral fracture there are varied reports regarding functional outcomes and complication rates observed among studies.

Hence the present study was conducted to evaluate the clinical and functional outcome of the proximal humeral internal locking system (PHILOS) technology in fixation of displaced proximal humeral fractures.

Objectives: To assess the functional and radiological outcome of the proximal humeral internal locking system (PHILOS) for displaced proximal humeral fractures in adults.

\section{Material and Method}

Study setting: Adults (>18years) with proximal humerus fractures admitted to department of orthopedics, GSL Medical College and General hospital Rajahmundry

Study duration: $1^{\text {st }}$ October 2015 to $31^{\text {st }}$ March 2017.

Type of study: Prospective observational study

Sampling methods: After confirmation of the proximal humerus fracture, if the patient fits into the above-said criteria was taken for study.

The study was approved by the institute's ethical committee. Patients were undergo Open reduction internal fixation with philos locking plating for the sustained fracture under general anaesthesia. Post-operative physiotherapy followed according to protocol, to evaluate the functional outcome. Fractures classified using Neer'sclassification $[11,25]$.

Inclusion criteria: All skeletally mature patients presenting with displaced proximal humerus fractures according to NEER two, three- and four-part fracture, with associated dislocation of the shoulder, undergoing revision surgery for failure of other implants, Failure of conservative treatment.

Exclusion criteria: Age less than 18 years, Pathologic fractures from primary or metastatic tumors, Open fractures and Poly trauma, Four-part fracture in elderly, with neurovascular deficits

Data collection procedure: On admission of the patient a careful history was elicited from the patients and or attendants of injury and the severity of trauma. The patients were then assessed clinically to evaluate their general condition and the local injury.

The local examination of injured shoulder was done for swelling, deformity loss of function and altered attitude. Local neurologic deficit of axillary nerve was also assessed by looking for anaesthetic patch over lateral aspect of shoulder.

After confirmation of the proximal humerus fracture, if the patient fits into the above-said criteria, the patients were informed about the study following which written, and informed consent was obtained.The patient was taken for surgery after routine investigation and after obtaining physician fitness towards surgery. 


\section{Original Research Article}

Surgical Approach: The geometry of proximal humerus is highly variable among individuals [10]. Knowledge of these abnormal kinematics helps in reduction and choosing the proper implants for fixation of these fractures [26,27]. Identification of rotator cuff tendons helps in the reduction of the tuberosity fragments by passing sutures [28]. Anatomical tuberosity reconstruction with intact rotator cuff is the key to good functional outcomes in complex proximal humerus fractures [29]. Gerber et al reported that the anterior humeral circumflex provides the major supplier to the head of the humerus and the posterior humeral circumflex supplies only a portion of the greater tuberosity and small posteroinferior part of the head [30]. The two different surgical approaches commonly used for surgical fixation of proximal humerus fractures places the variable risk of injuring theses arteries. Deltopectoral approach places the anterolateral ascending branch of the anterior humeral circumflex artery at risk during dissection. However, no such risks exist in the deltoid splitting approach (Figure 1 and 2).

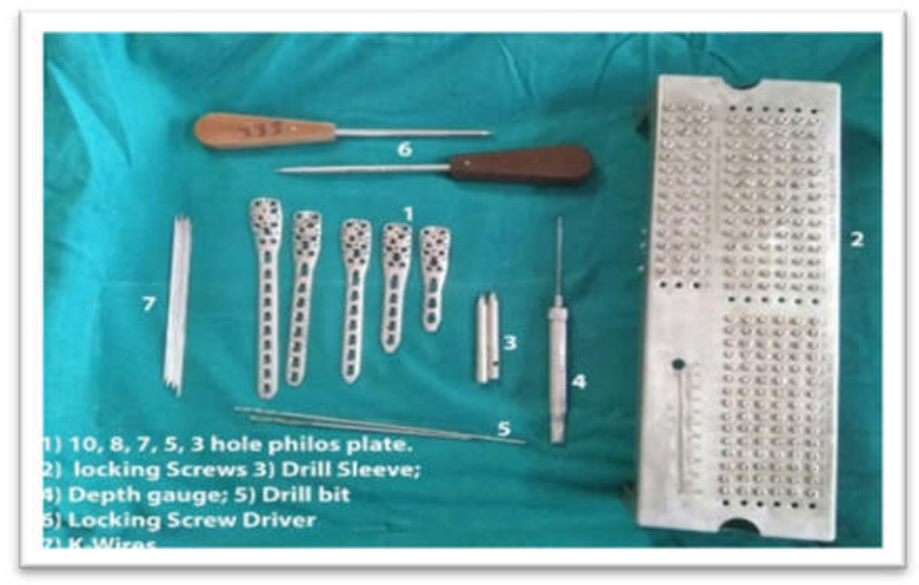

Fig-1: Philos plating instruments.

The patients were operated under general anesthesia. The surgical approach used were either "deltopectoral" or "deltoid splitting".

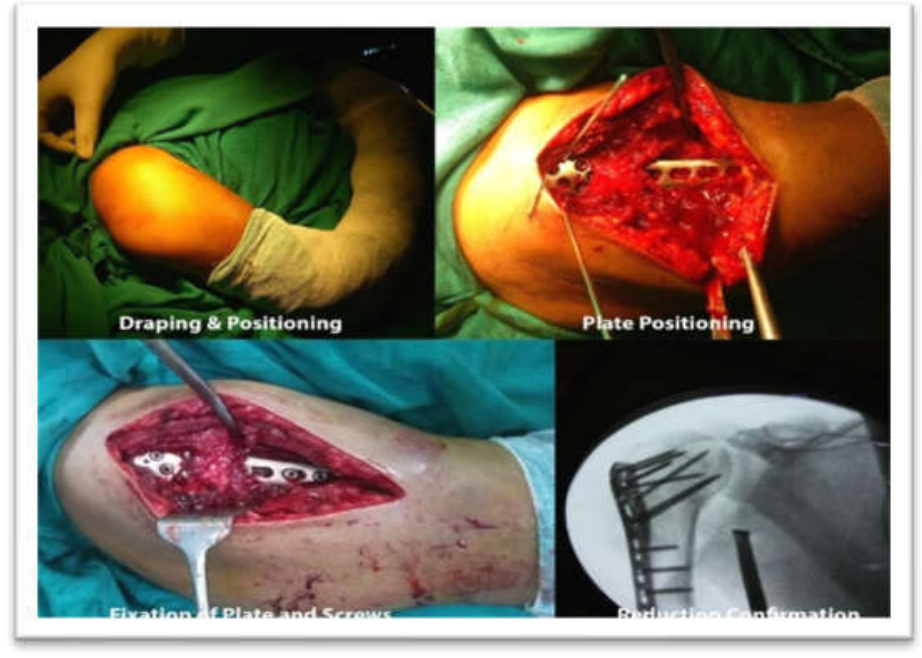

Fig-2: Intraoperative images of philos plating.

Postoperative management: All patients are immobilized in arm pouch with cuff and collar sling. Active assisted and passive exercises of the shoulder were done during the first three weeks, after which active range of motion of shoulder was started along with muscle strengthening exercises. All postoperative rehabilitation was done under the guidance of an experienced physiotherapist.

Follow up \& functional results: The shoulder functions were assessed using standard Constant-Murley score proforma at postoperative six weeks, three months \& six months [31,32]. The protocol mentioned in the Danish version of modified Constant- Murley score was followed to measure individual parameters [33]. 


\section{Original Research Article}

Statistical analysis: Descriptive statistics such as mean, SD, frequency and percentage was used. The comparison of the continuous variables with the categorical variables was analyzed by using Independent Student t-test, Mann-Whitney u test or One-way analysis of variance/ Krussel-Wallis test; whichever was appropriate based on the distribution of data and number of groups. The changes in the continuous outcome variables over time were analyzed by using repeated measures ANOVA test. A P - value of less than 0.05 was considered to be statistically significant. Data analysis was performed by using software SPSS v22.0.

\section{Results}

A total of Twenty-five patients with displaced two-part, three-part and four-part proximal humeral fracture were enrolled into the study and they were treated by open reduction and internal fixation with PHILOS plate.

Table-1: Injury related parameters.

\begin{tabular}{|c|c|c|}
\hline Parameters & Number of patients & Percentage \\
\hline Mode of injury & & 72 \\
\hline RTA & 18 & 28 \\
\hline Fall due to slip & 07 & 52 \\
\hline Limb involved & 13 & 48 \\
\hline Right Side & 12 & \\
\hline Left Side & & 40 \\
\hline Co-morbidity & 18 & 12 \\
\hline None & 02 & 32 \\
\hline Hypertension & 04 & 08 \\
\hline Diabetes Mellitus & 01 & \\
\hline C.A.D & & \\
\hline
\end{tabular}

In the present study the most common mechanism of injury was found to be road traffic accidents with a total of 18 ( $72 \%$ ) patients and rest 7 (28\%) were injured due to accidental fall on the ground (Table 1).

In the present study the right side proximal humeral fractrure occurred in $13(52 \%)$ Patients and left side proximal humeral fractrure occurred in 12 (48\%) patients respectively (Table 2).

Majority of the patients around 18 (72\%) doesn't have any co-morbidities, a total of 7 (28\%) patients had different comorbidities which includes; 4 (16\%) had diabetes mellitus, $2(8 \%)$ had hypertension, and $1(4 \%)$ had coronary artery disease.

Table-2: Neer's classification.

\begin{tabular}{|l|c|c|}
\hline Classification & Number of patients & Percentage \\
\hline 2 Part Fracture & 13 & 52 \\
\hline 3 Part Fracture & 08 & 32 \\
\hline 4 Part Fracture & 04 & 16 \\
\hline
\end{tabular}

According to Neer'sclassification, majority of the patients $13(52 \%)$ had displaced two-part, followed by $8(32 \%)$ had three-part and least $4(16 \%)$ had four-part proximalhumerus fractures

Table-3: Shoulder functional outcomes.

\begin{tabular}{|c|c|c|c|c|c|}
\hline Follow-up & N & CMS (Mean \pm SD) & Df & F & p- value \\
\hline 06 Weeks & 25 & $36.24 \pm 4.48$ & 2 & \multirow{2}{*}{130.61} & 0.000 \\
\hline 12 Weeks & 25 & $55.44 \pm 7.37$ & 72 & \\
\hline 06 Months & 25 & $69.84 \pm 9.41$ & & & \\
\hline
\end{tabular}

The Constant -Murley score achieved at the end of study period (6months) was 69.84 \pm 9.41 . The Constant-Murley score was significantly improved $(\mathrm{p}=0.000)$ over each successive follow-up period with the average improvement of around 19 scores between $1^{\text {st }}$ and $2^{\text {nd }}$ follow-up and around 15 score improvement between 2 nd and $3^{\text {rd }}$ follow-up (Table 3 ). 


\section{Original Research Article}

Table-4: Constant-Murley score grading.

\begin{tabular}{|c|c|c|}
\hline CMS Grading & Number of patients & Percent \\
\hline Poor (0-55) & 02 & 08 \\
\hline Moderate (56-70) & 11 & 44 \\
\hline Good (71-85) & 11 & 44 \\
\hline Excellent (86-100) & 01 & 04 \\
\hline Total & $\mathbf{2 5}$ & $\mathbf{1 0 0}$ \\
\hline
\end{tabular}

At six months follow up out of 25 patients, 02 patients had poor (constant score 0-55), 11 had moderate (constant score 56-70), 11 had good (constant score 71-85) and one had excellent (constant score 86-100) outcome (Table 4).

Table-5: Correlation between functional outcome and selected individual variables.

\begin{tabular}{|c|c|c|c|c|c|c|}
\hline & & $\ddot{8}_{4}^{\circ}$ & 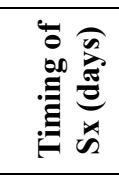 & 폴 & 氙 & 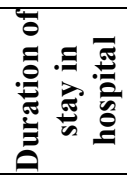 \\
\hline \multirow{5}{*}{ 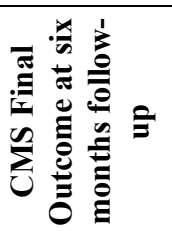 } & Pearson Correlation & -0.510 & & & & \\
\hline & Sig. (2-tailed) & 0.009 & & & & \\
\hline & Spearman's rho & & $-0.421 *$ & -0.048 & -0.338 & -0.101 \\
\hline & Sig. (2-tailed) & & 0.036 & 0.818 & 0.099 & 0.632 \\
\hline & $\mathbf{N}$ & 25 & 25 & 25 & 25 & 25 \\
\hline
\end{tabular}

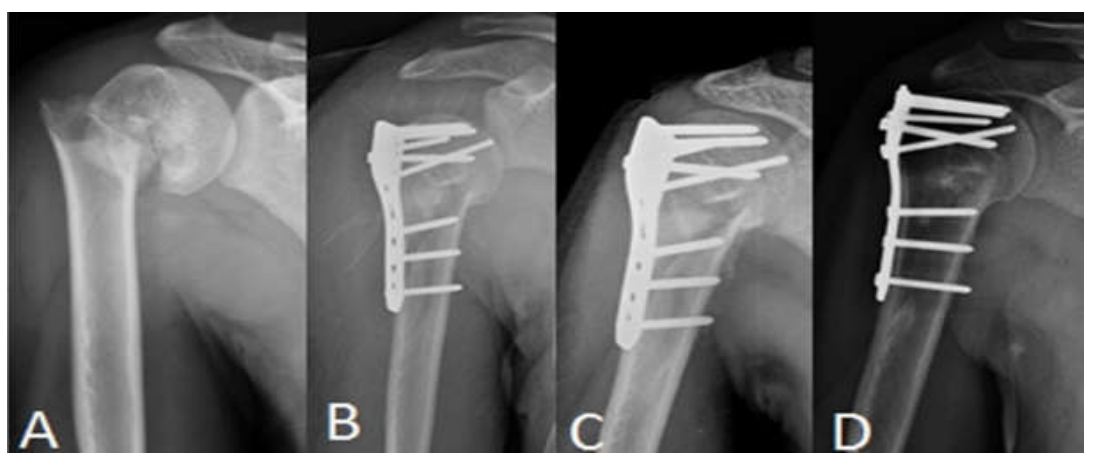

It is evident from the above table that there is a significant negative correlation between age and final outcome $(\mathrm{p}=0.009)$, as like delay in surgery and functional outcome $(\mathrm{p}=0.36)$ also having negative correlation. The is no correlation between final outcome with regard to other variables like Intra operative blood loos $(p=0.818)$, duration of surgery $(p=0.09)$, duration of hospital stay $(\mathrm{p}=0.632)$ (Table 5).

\section{Radiological pictures}

X-ray shoulder AP view: Preoperative (A), immediate postoperative (B), 3 months follow-up (C), and 6 months follow-up (D) (Figure 3).

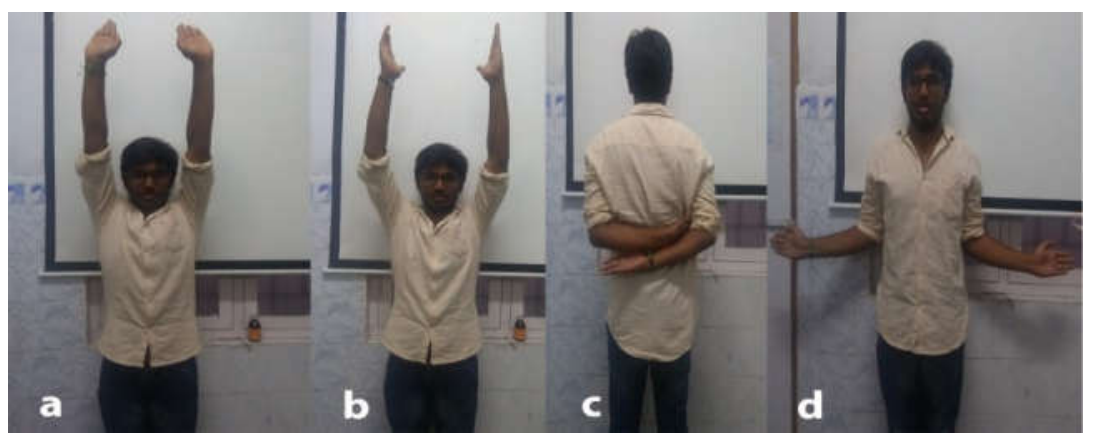

Fig-3: Right 2-part proximal humerus fracture treated with open reduction and internal fixation with proximal humerus locking plate 


\section{Discussion}

Locking plate technology is the most recent evaluation of devices which have been developed to overcome difficulty and complicationsfaced by previous fixation methods, and it shows promising results in recent studies [9,34]. The ages ranged from 22 years to 62 years withthe overall mean age of the patient was $43.52 \pm 13.04$ years, Majority of the patients i.e. $14(56 \%)$ were from age group of 19-49 years and 50-75 years age group has 11 (44\%) respectively. Among 25 patients, 16 (64\%) of the respondents are male and about $9(36 \%)$ of them are female.

Most of the patients had two-part (52\%) followed by three-part (32\%) and four-part (16\%) proximal humerus fractures. This is in accordance with the results of epidemiological studies conducted by Court-Brown et al. [35] and Roux et al [36] who stated that the most common displaced fracture pattern was 2-part fractures followed by 3 parts and 4 parts respectively. But this is in contrast to the findings of Vijayvargiya et al. [23], most of the fractures observed are three-part (46.1\%) followed by four- part (34.7\%) and least number are two-part (19.2\%) proximal humerus fractures. Similarly, Erasmo et al.observed a higher number of three-part fractures (40), compared to four- part (35) and two-part (2) among a total number of 81 patients with 82 proximal humeral humerus fractures [37].

In the present study, it was observed that road traffic accident was the most common mode of injury (72\%) followed by simple falls (28\%). This is in contrast to the earlier epidemiological studieswhich state fall as the most common mode of injury [3,35,36]. Vijayvargiya et al. study reported fall $(53.8 \%)$ is the predominant mode of injury followed by road traffic accidents (46.2\%) [23].

In the present study at the time of injury majority of fracture $13(52 \%)$ showed valgus displacement of the head followed by 9 (36\%) showed varus displacement and $3(12 \%)$ shows normal alignment. The average head-shaft angle of proximal humeral fracture after injury is $136.8 \pm$ 45.5 .

The average delay before surgery was two days which is similar to the study conducted by Menendez et al which states that the delay before surgery should not be later than three days to avoid inpatient adverse events, postoperative length of stay [38]. However, in the present study it was found that $24 \%$ of the patients got operated in 3-6 days of span after injury. The reasons behind the delay were due to their comorbid condition's patients were not fit for anaesthesia immediately. Thus, surgical fitness had to be ensured before surgery. On analysis, it was found statistically significant correlation between delay in surgery and functional outcome at six months follow-up according to Spearman's Rho correlation test $(\mathrm{p}=0.036)$. In the present study, Deltoid Split approach was used in $21(84 \%)$ of patients for open reduction and internal fixation of proximal humeral fracture whereas for other $4(16 \%)$ of patient's deltoid-splitting approach was used. Mean duration of surgery in the present study was 114 minutes. Mean duration of surgery in the deltoid split group was 114 minutes and mean duration of surgery in the deltopectoral group was 112 minutes with no significant difference in duration between two surgical approaches $(\mathrm{p}=0.267)$. Buecking et al. reported an average time taken for surgery in deltopectoral approach was 67 minutes where as in deltoid split approach was 62 minutes [39] whereas Waliulah et al. reported 84minutes for deltopectoral approach and 72 minutes for the deltoid split approach. This higher operating time in the present study was because multiple surgeons were involved in operating these cases, whose training and experience varied [40].

In the present study, average Constant-Murley score observed among all 25 patients with two-part, three-part and four-part proximal humerus fractures treated with proximal humeral locking plate at the end of six months follow-up was 70. The reported Constant-Murley score is varied among the literature. Thyagarajanet al. [41], Geiger et al. [42], Handschin et al. [43], Aksu et al. [44] studies reported less mean Constant-Murley score $(<70)$ compared to the present study. Fazal and Haddad et al. [45], Kettler et al. [46] studies reported mean Constant-Murley score of 70 as equivalent to the present study. Whereas Moonot et al. [47], Hirschmannet al. [20], Brunner etal. [48], Vijayvargiyaet al. [23], Martetschlgeret al. [49], and Erasmo et al. [37], reported slightly higher mean ConstantMurley score $(>67)$ than the present study. The variations in reported Constant-Murley score among different studies attribute to a multitude of reasons like the average age of patients, various follow-up periods and as most of the studies are Western studies with the difference in physical characteristics of patients with individual race.

Vijayvargiya et al. study, reported mean Constant-Murley score of 72.5 after 6 months follow-up [23]. The reported score was higher compared to the present study. Similarly, Erasmo et al. reported a Constant- Murley score of 75 among 82 patients who underwent locking plate fixation for two-part, three-part and four-part proximal humerus fractures [37]. But the follow-up period was 32 weeks which is comparably higher than the present study. Kumar et al. study reported, the constant-Murley score observed was 79 at a mean follow-up period of 30 months [50]. The high Constant-Murley score reported in this compared to 


\section{Original Research Article}

the present study may be due to the younger age of participants (mean age of 38 years) and longer follow-up period. Analysis of individual parameters of the ConstantMurley score in the present study at the end of 6 months follow-up showed pain score of 12.7, Activities of daily living 16.3, the range of motion 31.1 and strength 9.5. These results are consistent with results reported in other studies. Iacobellis et al. reported a pain score of 10.6, activity of daily living 15.3, the range of motion 26.8 and strength 10.3 [51]. Strength score is less in the present study compared to above study. It can be explained by the differences in physical built of the European and Indian population, and gender variation and follow up period is also very long in their study (21 months) compared to 6 months follow up in the present study.

In the present study, 01 of the patient $(04 \%)$ had excellent (constant score 86-100) 11 patients (44\%) hadgood (constant score 71-85), 11 patients (44\%) had moderate (constant score 56-70) and only 2 patients (08\%) had poor (constant-score 0-55) functional outcome. These results are consistent with result found in other studies. Vijayvargiya et al. study reported 8 patients with the good score, 10 patients with the moderate score, 6 patients with excellent outcome and 2 patients with poor outcome [23]. Similarly, Erasmo et al study with 82 patients of proximal humerus fractures with an average follow-up of 32 months reportedexcellent scores for 8 patients, good for 52, moderate for 17 and poor for 5 patients [37]. However, Gieger et al. study reported excellent to good results in 16 patients, moderate in 1 patient and poor in 11 patients [42].

In the present study it was found that among 52\% (13) of two-part fractures; 4\% (1) patients had excellent, 32\% (8) patients had good, $12 \%$ (3) patients had moderate and 1 (4\%) patients had poor outcome. Among 32\% (8) of threepart fractures $8 \%$ (2) patients had good and 24\% (6) patients had moderate outcome. Among 16\% (4) of ourpart fractures $4 \%$ (1) patients had good, $8 \%$ (2) patients had moderate and 4\% (1) patients had poor outcome. It was compared that the results of two-part, three-part and four-part fracture types as per Constant score. It was found no significant difference in Constant-Murley score among two-part, three-part and four-part proximal humeral fractures (73.2 Vs 67.5 Vs 63.5) $(\mathrm{p}=0.135)$. These findings are similar to reported by Vijayvargiya et al [23] study (80.8 Vs 71.3 Vs 69.3). This study, like the present study, didn't find any significant difference in outcomes between patients with 2-part, 3-part and 4-part fractures.

In the present study it was found that among 64\% (16) of no osteoporotic patients; $4 \%$ (1) of patients had excellent, $36 \%$ (09) patients had good, $24 \%$ (6) of patients had moderate and none of the patients had poor outcome. Likewise, among 36\% (09) of co-morbid patients; $8 \%$ (2) of the patients had good and 20\% (5) of the patients had moderate and $08 \%$ (2) of the patients had poor outcome. The estimated average of functional outcome at six months follow up for the group with osteoporosis is 63.78 and for the group without osteoporosis is 73.25 ( $p=0.023)$, which implies there is a significant difference in functional outcome with regard to the presence of the absence of osteoporosis.

In the present study, it was found that among $84 \%$ (21) of Deltoid splitting approach patients; (4\%) patients had excellent, 9(36\%) had good,10(40\%) had moderate and $1(4 \%)$ had poor outcome. Likewise, among $4(16 \%)$ of Delto pectoral approach patients; $2(8 \%)$ patients had good and $1(4 \%)$ patients had moderate and $1(04 \%)$ patients had poor outcome. The estimated average of functional outcome at six months follow up for Deltoid splitting approach is $70.29 \pm 8.69$ and for Delto pectoral approach group is $67.50 \pm 14.01$. The present study didn't find any statistical difference $(p=0.724)$ between the functional outcomesin patients who underwent proximal humerus fracture fixation through deltoid-splitting or deltopectoral approach. These findings are similar to Martetschlager et al. study which compared the clinic-radiological outcomes of deltoid-splitting or deltopectoral approach in fixation of proximal humerus fractures [49].

In the present study, time for the union was 3 to 6 months. All fractures except one united at the end of study period. Vijayvargiya et al. study reported mean time to union was 12.3 weeks (9-15 weeks) in 26 patients studied [23].

In the present study, $4 \%$ of excellent functional outcome, $44 \%$ of good functional outcomes, as well as $44 \%$ of moderatefunctional outcomes and only $08 \%$ of poor functional outcomes, among patients with two-part, threepart and four-part proximal humerus fracture treated with locking plate. In the present study, observed complication rate among $28 \%$ participants. The present study is of the opinion that proximal humerus locking plate is an effective system for stabilizing two-part, three-part and four-part proximal humerus fractures but one should be wary of potential complications.

Limitations of the present study: Further study in large number of patients is required to comment functional and radiological outcome of the proximal humeral internal locking system (PHILOS) for displaced proximal humeral fractures.

\section{Conclusion}

In conclusion, the proximal humeral locking plate seems to be an adequate device for the fixation of displaced twopart, three-part and four-part proximal humerus fractures 


\section{Original Research Article}

as $92 \%$ of the present study population had "excellent to moderate" functional outcomes. Due to stable fixation, early functional aftercare is possible and allows the patient to regain good shoulder function and resume normal activities much earlier.

Proximal humerus locking plate is an effective system for stabilizing these fractures, but the surgeon should be aware of potential complications Additional studies with larger cohorts and longer follow-ups are necessary to better define the appropriate indications and expected outcomes of this technology.

\section{What the study adds to the existing knowledge?}

Literature on functional and radiological outcome of the proximal humeral internal locking system (PHILOS) for displaced proximal humeral fractures has shown different conclusions which make a meaningful adding in existing literature by conducting the present study in an area to timely recognition and understanding of common issues related to PHILOS.

\section{Author's contribution}

Dr. NV Narasimha Rao: Study design and manuscript preparation.

Dr. Challa Supradeeptha: Study design and manuscript preparation

Funding: No funding sources

Conflict of interest: None declared

Ethical Approval: This study was approved by the Institutional Ethics Committee

\section{References}

1. Court-Brown CM, Garg A, McQueen MM. The epidemiology of proximal humeral fractures. Acta Orthop Scand. 2001;72(4):365-371.

2. Kristiansen B, Barfod G, Bredesen J, Erin-Madsen J, Grum B, Horsnaes MW, et al. Epidemiology of proximal humeral fractures. Acta Orthop Scand. 1987;58(1):75-77.

3. Palvanen M, Kannus P, Niemi S, Parkkari J. Update in the epidemiology of proximal humeral fractures. Clin Orthop Relat Res. 2006;442:87-92. doi: 10.1097/01.blo. 0000194672.79634 .78 .

4. Holloway KL, Bucki-Smith G, Morse AG, BrennanOlsen SL, Kotowicz MA, Moloney DJ, et al. Humeral Fractures in South-Eastern Australia: Epidemiology and Risk Factors. Calcif Tissue Int. 2015;97(5):453-465. doi: 10. 1007/s00223-015-0039-9. Epub 2015 Jul 14.
5. Sumrein BO, Huttunen TT, Launonen AP, Berg HE, Felländer-Tsai L, Mattila VM. Proximal humeral fractures in Sweden-a registry-based study. Osteoporos Int. 2017; 28 (3): 901-907. doi: 10.1007/s00198-016-3808-z. Epub 2016 Oct 27.

6. Park C, Jang S, Lee A, Kim HY, Lee YB, Kim TY, et al. Incidence and mortality after proximal humerus fractures over 50 years of age in South Korea: national claim data from 2008 to 2012. J Bone Metab. 2015; 22 (1): 17-21. doi: 10.11005/jbm.2015.22.1.17.

7. Karl JW, Olson PR, Rosenwasser MP. The Epidemiology of Upper Extremity Fractures in the United States, 2009. J Orthop Trauma. 2015;29(8): e242-244. doi: 10. 1097/BOT.0000000000000312.

8. Lind T, Krøner K, Jensen J. The epidemiology of fractures of the proximal humerus. Arch Orthop Trauma Surg. 1989;108(5):285-287.

9. Boileau P, Walch G. The three-dimensional geometry of the proximal humerus. Implications for surgical technique and prosthetic design. J Bone Joint Surg Br. 1997; 79 (5): 857-865.

10. Burkhart KJ, Dietz SO, Bastian L, Thelen U, Hoffmann R, Müller LP. The treatment of proximal humeral fracture in adults. Dtsch Arztebl Int. 2013; 110 (35-36):591-597. doi: 10.3238/arztebl. 2013. 0591. Epub 2013 Sep 2.

11. Zyto K, Ahrengart L, Sperber A, Törnkvist H. Treatment of displaced proximal humeral fractures in elderly patients. J Bone Joint Surg Br. 1997; 79(3): 412-417.

12. Koval KJ, Gallagher MA, Marsicano JG, Cuomo F, McShinawy A, Zuckerman JD. Functional outcome after minimally displaced fractures of the proximal part of the humerus. J Bone Joint Surg Am. 1997;79(2):203-207.

13. Hodgson SA, Mawson SJ, Stanley D. Rehabilitation after two-part fractures of the neck of the humerus. J Bone Joint Surg Br. 2003;85(3):419-422.

14. McKoy BE, Bensen CV, Hartsock LA. Fractures about the shoulder: conservative management.Orthop Clin North Am. 2000;31(2):205-216. doi: https://doi.org/ 10. 1016/ S0030-5898(05)70141-3.

15. Gaebler C, McQueen MM, Court-Brown CM. Minimally displaced proximal humeral fractures: epidemiology and outcome in 507 cases. Acta Orthop Scand. 2003; 74(5):580-585 


\section{Original Research Article}

16. Hanson B, Neidenbach P, de Boer P, Stengel D. Functional outcomes after nonoperative management of fractures of the proximal humerus. J Shoulder Elbow Surg. 2009;18(4):612-621. doi: 10.1016/j.jse.2009.03.024.

17. Poeze M, Lenssen AF, Van Empel JM, Verbruggen JP. Conservative management of proximal humeral fractures: can poor functional outcome be related to standard transscapular radiographic evaluation? J Shoulder Elbow Surg. 2010;19(2):273-281. doi: 10.1016/j.jse.2009.07.066.

18. Azar FM, Canale ST, Beaty JH. Campbell's Operative Orthopaedics. $13^{\text {th }}$ ed. Elsevier - Health Sciences Division; 2017. $4776 \mathrm{p}$.

19. Thanasas C, Kontakis G, Angoules A, Limb D, Giannoudis P. Treatment of proximal humerus fractures with locking plates: a systematic review. J Shoulder Elbow Surg. 2009;18(6):837-844. doi: 10.1016/j.jse.2009.06.004. Epub 2009 Sep 12.

20. Hirschmann MT, Fallegger B, Amsler F, Regazzoni P, Gross T. Clinical longer-term results after internal fixation of proximal humerus fractures with a locking compression plate (PHILOS). J Orthop Trauma. 2011;25(5):286-293. doi: 10.1097/BOT.0b013e3181f2b20e.

21. Martetschläger F, Siebenlist S, Weier M, Sandmann G, Ahrens P, Braun K, et al. Plating of proximal humeral fractures. Orthoped. 2012;35(11):e1606-e1612.

22. Kumar GNK, Sharma G, Sharma V, Jain V, Farooque $\mathrm{K}$, Morey V. Surgical treatment of proximal humerus fractures using PHILOS plate. Chin J Traumatol. 2014;17 (5): 279-284. doi: https://doi.org/10.3760/cma.j.issn.10081275. 2014.05.006.

23. Vijayvargiya M, Pathak A, Gaur S. Outcome Analysis of Locking Plate Fixation in Proximal Humerus Fracture. J Clin Diagn Res. 2016;10(8):RC01-RC05. doi: 10.7860/ JCDR/ 2016/18122.8281.

24. Misra A, Kapur R, Maffulli N. Complex proximal humerus fractures in adults - a systematic review of management. Injury. 2001;32(5):363-372. doi: 10.1016/ S0020-1383(00)00242-4.

25. Neer CS. Displaced proximal humeral fractures. II. Treatment of three-part and four-part displacement. J Bone Joint Surg Am. 1970;52(6):1090-1103.

26. Cruickshank D, Lefaivre KA, Johal H, MacIntyre NJ, Sprague SA, Scott $T$, et al. A scoping review of biomechanical testing for proximal humerus fracture implants. BMC Musculoskelet Disord. 2015;16:175. doi: 10.1186/s12891-015-0627-x.

27. Pinkowsky GJ, ElAttrache NS, Peterson AB, Akeda M, McGarry MH, Lee TQ. Partial-thickness tears involving the rotator cable lead to abnormal glenohumeral kinematics. J Shoulder Elbow Surg.2017; 26(7): 11521158. doi: 10.1016/j. jse.2016. 12.063. Epub 2017 Mar 27.

28. Jordan RW, Modi CS. A review of management options for proximal humeral fractures. Open Orthop J. 2014; 8:148-156. doi: 10.2174/1874325001408010148.

29. Gregory TM, Vandenbussche E, Augereau B. Surgical treatment of three and four-part proximal humeral fractures. OrthopTraumatol Surg Res. 2013; 99(1): S197S207. doi: 10.1016/j.otsr.2012.12.006. Epub 2013 Jan 16.

30. Gerber C, Schneeberger AG, Vinh TS. The arterial vascularization of the humeral head. An anatomical study. J Bone Joint Surg Am. 1990;72(10):1486-1494.

31. Darder A, Darder A, Sanchis V, Gastaldi E, Gomar F. Four-part displaced proximal humeral fractures: operative treatment using Kirschner wires and a tension band. J Orthop Trauma. 1993;7(6):497-505.

32. Constant CR, Murley AH. A clinical method of functional assessment of the shoulder. Clin OrthopRelat Res. 1987;214:160-164.

33. Moeller AD, Thorsen RR, Torabi TP, Bjoerkman A$\mathrm{SD}$, Christensen EH, Maribo T, et al. The Danish version of the modified Constant-Murley shoulder score: reliability, agreement, and construct validity. J Orthop Sports Phys Ther. 2014;44(5):336-340. doi: 10.2519/ jospt. 2014.5008. Epub 2014 Mar 27.

34. Thanasas C, Kontakis G, Angoules A, Limb D, Giannoudis P. Treatment of proximal humerus fractures with locking plates: a systematic review. J Shoulder Elbow Surg. 2009;18(6):837-844. doi: 10.1016/j.jse.2009.06.004. Epub 2009 Sep 12.

35. Court-Brown CM, Caesar B. Epidemiology of adult fractures: A review. Injury. 2006;37(8):691-697. doi: https://doi.org/10.1016/j.injury.2006.04.130.

36. Roux A, Decroocq L, El Batti S, Bonnevialle N, Moineau G, Trojani C, et al. Epidemiology of proximal humerus fractures managed in a trauma center. OrthopTraumatol Surg Res. 2012; 98(6):715-719. doi: 10.1016/j.otsr.2012.05.013. Epub 2012 Sep 19. 


\section{Original Research Article}

37. Erasmo R, Guerra G, Guerra L. Fractures and fracturedislocations of the proximal humerus: A retrospective analysis of 82 cases treated with the Philos(®) locking plate. Injury. 2014;45(6):S43-S48. doi: 10.1016/j.injury. 2014. 10.022. Epub 2014 Nov 4.

38. Menendez ME, Ring D. Does the timing of surgery for proximal humeral fracture affect inpatient outcomes? J Shoulder Elbow Surg. 2014;23(9):1257-1262. doi: 10. 1016 /j. jse.2014.03.010. Epub 2014 Jun 9.

39. Buecking B, Mohr J, Bockmann B, Zettl R, Ruchholtz S. Deltoid-split or deltopectoral approaches for the treatment of displaced proximal humeral fractures? Clin OrthopRelat Res. 2014;472(5):1576-1585. doi: 10.1007/ s11999-013-3415-7. Epub 2013 Dec 11.

40. Waliullah S, Kumar A. Difference between radiological and functional outcome with deltoid-splitting approach versus deltopectoral approach for the management of proximal humeral fractures with philos plate. J Orthopaed All Sci. 2013;1(1):14-17. doi: 10.4103/ 2319-2585.117382.

41. Thyagarajan DS, Haridas SJ, Jones D, Dent C, Evans R, Williams R. Functional outcome following proximal humeral interlocking system plating for displaced proximal humeral fractures. Int J Shoulder Surg. 2009;3 (3): 57-62. doi: 10.4103/0973-6042.59971.

42. Geiger EV, Maier M, Kelm A, Wutzler S, Seebach C, Marzi I. Functional outcome and complications following PHILOS plate fixation in proximal humeral fractures. Acta Orthop Traumatol Turc. 2010;44(1):1-6. doi: 10.3944/ AOTT.2010.2270.

43. Handschin AE, Cardell M, Contaldo C, Trentz O, Wanner GA. Functional results of angular-stable plate fixation in displaced proximal humeral fractures. Injury. 2008; 39 (3): 306-313. doi: 10.1016/j. injury. 2007.10. 011.

44. Aksu N, Göğüş A, Kara AN, Işiklar ZU. Complications encountered in proximal humerus fractures treated with locking plate fixation. Acta Orthop Traumatol Turc. 2010; 44(2):89-96. doi: 10.3944/AOTT.2010.2313.

45. Fazal MA, Haddad FS. Philos plate fixation for displaced proximal humeral fractures. J Orthop Surg (Hong Kong). 2009;17(1):15-18. doi: https://doi.org/10. $1177 / 230949900901700104$.

46. Kettler M, Biberthaler P, Braunstein V, Zeiler C, Kroetz M, Mutschler W. [Treatment of proximal humeral fractures with the PHILOS angular stable plate. Presentation of 225 cases of dislocated fractures]. Unfallchirurg. 2006; 109(12):1032-1040. doi: https://doi. org / 10.1007/s00113-006-1165-7.

47. Moonot P, Ashwood N, Hamlet M. Early results for treatment of three- and four-part fractures of the proximal humerus using the PHILOS plate system. J Bone Joint Surg Br. 2007;89(9):1206-1209. doi: https://doi.org/10. 1302/ 0301-620X.89B9.18528.

48. Brunner F, Sommer C, Bahrs C, Heuwinkel R, Hafner $\mathrm{C}$, Rillmann $\mathrm{P}$, et al. Open reduction and internal fixation of proximal humerus fractures using a proximal humeral locked plate: a prospective multicenter analysis. J Orthop Trauma. 2009;23(3):163-172. doi: 10.1097/BOT. 0b013e $3181920 \mathrm{e} 5 \mathrm{~b}$.

49. Doshi C, Sharma GM, Naik LG, Badgire KS, Qureshi F. Treatment of proximal humerus fractures using PHILOS plate. Journal of clinical and diagnostic research: JCDR. 2017;11(7): RC10-RC13. doi: 10.7860/JCDR/ $2017 / 26782.10304$.

50. Manek V, Venkatachalam K, Reddy V. Proximal humeral internal locking osteosynthesis for surgical fixation for displaced two part to four part fractures: A prospective study. Int J Orthopaed. 2018;4(2):640-648. doi: https://doi.org/10.22271/ortho.2018.v4.i2j.93.

51. Iacobellis C, Fountzoulas K, Aldegheri R. Plating of proximal fracture of the humerus: a study of 30 cases. Musculoskel Surg. 2011; 95(1): 43-48. doi: 10.1007/ s12306-011-0103-1. Epub 2011 Mar 4.

\section{How to cite this article?}

Rao N.V.N, Supradeeptha C. Study on functional outcome of the proximal humeral internal locking system (PHILOS) for displaced proximal humeral fractures in adults. Surgical Update: Int J surg Orthopedics.2019;5(5):355-364.doi:10.17511/ ijoso.2019.105.07 